\title{
Pengaruh Struktur Aktiva dan Profitabilitas terhadap Struktur Modal Perusahaan Makanan dan Minuman
}

\author{
Ghia Ghaida Kanita \\ Fakultas Ekonomi Universitas Padjadjaran \\ J1. Dipati Ukur No. 35 Bandung 40132 \\ E-Mail: ghia_ghaida@yahoo.co.id
}

\begin{abstract}
This study aims to determine whether the asset structure and profitability have an influence on the capital structure. The object of research is taken from food and beverage companies listed in Indonesia Stock Exchange 2007-2009 period. The method used in this research is descriptive verification, regression equation used is a model of the data panel. The result of this research is the asset structure has no significant effect on capital structure, while profitability has a significant impact on the capital structure of food and beverage companies listed on the Stock Exchange 2007-2009 period.
\end{abstract}

Keywords: capital structure, asset structure, profitability.

\begin{abstract}
ABSTRAK
Penelitian ini bertujuan untuk mengetahui apakah struktur aktiva dan profitabilitas memiliki pengaruh terhadap struktur modal. Objek penelitian yang diambil adalah perusahaan makanan dan minuman yang terdaftar di Bursa Efek Indonesia (BEI) periode 2007-2009. Metode yang digunakan dalam penelitian ini adalah deskriptif verifikatif, persamaan regresi yang digunakan adalah model panel data. Hasil penelitian menunjukkan bahwa struktur aktiva tidak memiliki pengaruh signifikan terhadap struktur modal, sedangkan profitabilitas memiliki pengaruh signifikan terhadap struktur modal pada perusahaan makanan dan minuman yang terdaftar di BEI periode 2007-2009.
\end{abstract}

Kata Kunci: struktur modal, struktur aktiva, profitabilitas. 


\section{PENDAHULUAN}

Setiap perusahaan ingin memiliki manajemen yang baik agar tujuan perusahaan bisa tercapai. Salah satu bagian penting dalam manajemen perusahaan adalah keuangan. Manajer keuangan memiliki tugas untuk mengambil keputusan keuangan. Manajer keuangan harus berhati-hati serta memperhitungkan secara teliti agar keputusan investasi dan pendanaan dapat mencapai tujuan perusahaan. Tujuan perusahaan adalah memaksimalkan kesejahteraan pemilik saham.

Keputusan pendanaan menentukan jumlah dan sumber dana yang diperlukan perusahaan tersebut. Komposisi pendanaan perusahaan terdiri dari modal sendiri dan utang yang berasal dari pihak luar. Utang didapatkan dengan menerbitkan obligasi dan berbagai utang jangka panjang lainnya. Kombinasi dari modal sendiri dan utang jangka panjang disebut struktur modal. Oleh karena itu penentuan modal sendiri dan utang jangka panjang harus dilakukan dengan cermat agar tujuan perusahaan tercapai. Dalam Proses keuangan menempati posisi penting dalam manajemen perusahaan, sebab harus dipastikan bahwa keberlanjutan keuangan sangat diperlukan bagi pengembangan perusahaan dan dalam memperbaiki persaingan dalam dunia usaha (Šarlija dan Harc, 2012).

Berperannya stuktur modal dalam keberhasilan perusahaan tercermin dari hasil beberapa penelitian terdahulu yang menunjukkan bahwa struktur modal mempengaruhi secara positif terhadap kinerja keuangan perusahaan dan kepada keuntungan para pemegang saham (shareholders wealth) (Mujahid dan Akhtar, 2014; Saleem, F. dan Rafique, B., 2013). Dalam penelitian lainnya disebutkan bahwa pengeloaan stuktur modal yang baik dan terus dipertahannkan, akan meminimumkan cost of capital, dan pada akhirnya dapat meningkatkan kinerja dan nilai perusahaan (Muritala, 2012).

Struktur modal adalah masalah yang penting, karena keputusan tentang struktur modal menimbulkan risiko yang harus ditanggung pemilik perusahaaan disamping menimbulkan tingkat pengembalian tertentu. Setiap sumber dana memiliki tingkat risiko dan tingkat pengembalian yang berbeda-beda. Pendanaan melalui utang menyebabkan trade-off antara tingkat risiko dan tingkat pengembalian.
Penambahan utang dapat memperbesar risiko perusahaan sehingga dapat menurunkan nilai perusahaan. Namun disisi lain peningkatan risiko menyebabkan tingkat pengembalian yang diharapkan meningkat sehingga dapat menaikkan nilai perusahaan. Bagaimana hubungan antara struktur modal dengan nilai perusahaan tercermin dari hasil penelitian yang dilakukan oleh Sadeghian (2012) yang menunjukkan bahwa peningkatan dalam berbagai jenis utang perusahaan memberikan dampak negatif terhadap kinerja perusahaan. Penemuan lainnya adalah perusahaan-perusahaan yang hanya mengandalkan penciptaan aset melalui utang, tanpa memperhatikan ukuran perusahaan dan faktor-faktor penting lainnya, tidak akan dapat memperoleh kinerja yang baik.

Struktur modal yang optimal adalah kombinasi utang dan ekuitas yang akan memaksimalkan nilai perusahaan. Perusahaan dalam praktiknya sulit untuk mendapatkan struktur modal yang optimal. Namun manajemen perusahaan memiliki struktur modal sasaran yang spesifik, yang apabila sasaran tersebut tercapai maka dapat diasumsikan struktur modal perusahaan sudah optimal, meskipun hal ini akan berubah dari waktu ke waktu.

Industri makanan dan minuman sebagai salah satu industri yang memberikan kontribusi tertinggi terhadap Produk Domestik Bruto (PDB) sektor Industri pengolahan Indonesia. Pada tahun 2012, industri makanan dan minuman berkontribusi sebesar $7,14 \%$ terhadap PDB sektor industri pengolahan Indonesia (Tabel 1.), dengan angka pertumbuhan yang terus meningkat setiap tahunnya (Tabel 2.).

Peningkatan kontribusi industri makanan dan minuman ini merupakan sebagai dampak dari peningkatan kinerja industri ini yang ditandai dengan terus bertambahnya jumlah perusahaan yang bergerak dalam industri ini. Jika pada tahun 2002, perusahaan pada industri makanan dan minuman berjumlah 4.559 unit, maka pada tahun 2009 jumlahnya meningkat menjadi 6.560 unit (Tabel 3.).

Struktur modal bagi pemegang saham dapat memberikan informasi penting tentang bagaimana kondisi perusahaan, karena komposisi pendanaan akan mempengaruhi nilai perusahaan. Banyak teori struktur modal yang dikemukakan para ahli namun yang digunakan dalam penelitian ini hanya pecking order theory. 
Tabel 1. Kontribusi Industri Makanan dan Minuman terhadap PDB Sektor Industri Pengolahan Non Migas (\%)

\begin{tabular}{clrrrrrr}
\hline No. & \multicolumn{1}{c}{ Lapangan Usaha } & $\mathbf{2 0 0 7}$ & $\mathbf{2 0 0 8}$ & $\mathbf{2 0 0 9}$ & $\mathbf{2 0 1 0}$ & $\mathbf{2 0 1 1}$ & $\mathbf{2 0 1 2}$ \\
\hline 1. & Makanan, minuman, dan tembakau & 6.68 & 7.00 & 7.50 & 7.23 & 7.37 & 7.14 \\
2. & Tekstil, barang kulit, dan alas kaki & 2.37 & 2.12 & 2.08 & 1.93 & 1.93 & 1.86 \\
3. & Barang kayu dan hasil hutan lainnya & 1.39 & 1.48 & 1.43 & 1.25 & 1.14 & 1.09 \\
4. $\quad$ Kertas dan barang cetakan & 1.15 & 1.05 & 1.09 & 1.02 & 0.93 & 0.88 \\
5. $\quad$ Pupuk, kimia, dan barang dari karet & 2.80 & 3.11 & 2.91 & 2.74 & 2.55 & 2.59 \\
6. $\quad$ Semen dan barang galian bukan logam & 0.83 & 0.81 & 0.78 & 0.71 & 0.68 & 0.69 \\
7. $\quad$ Logam Dasar besi dan baja & 0.58 & 0.59 & 0.48 & 0.42 & 0.42 & 0.42 \\
8. $\quad$ Alat angkutan, mesin, dan peralatannya & 6.44 & 6.67 & 6.18 & 6.05 & 5.75 & 5.67 \\
9. $\quad$ Barang lainnya & 0.19 & 0.18 & 0.18 & 0.16 & 0.15 & 0.15 \\
Total Industri Pengolahan Non Migas & 22.43 & 23.01 & 22.61 & 21.51 & 20.92 & 20.47 \\
\hline
\end{tabular}

Sumber: Kemenperin

Tabel 2. Pertumbuhan Industri Pengolahan Non Migas (\%)

\begin{tabular}{rlrrrrrr}
\hline No. & \multicolumn{1}{c}{ Lapangan Usaha } & $\mathbf{2 0 0 7}$ & $\mathbf{2 0 0 8}$ & $\mathbf{2 0 0 9}$ & $\mathbf{2 0 1 0}$ & $\mathbf{2 0 1 1}$ & $\mathbf{2 0 1 2}$ \\
\hline 1. & Makanan, minuman, dan tembakau & 5.05 & 2.34 & 1.12 & 2.78 & 9.19 & 8.19 \\
2. & Tekstil, barang kulit, dan alas kaki & $(3.68)$ & $(3.64)$ & 0.60 & 1.77 & 7.52 & 1.41 \\
3. & Barang kayu dan hasil hutan lainnya & $(1.74)$ & 3.45 & $(1.38)$ & $(3.47)$ & 0.35 & $(0.86)$ \\
4. & Kertas dan barang cetakan & 5.79 & $(1.48)$ & 6.34 & 1.67 & 1.50 & 0.50 \\
5. & Pupuk, kimia, dan barang dari karet & 0.57 & 4.46 & 1.64 & 4.70 & 3.95 & 9.19 \\
6. & Semen dan barang galian bukan logam & 3.40 & $(1.49)$ & $(0.51)$ & 2.18 & 7.19 & 6.11 \\
7. & Logam Dasar besi dan baja & 1.69 & $(2.05)$ & $(4.26)$ & 2.38 & 1.31 & 5.57 \\
8. & Alat angkutan, mesin, dan peralatannya & 9.73 & 9.79 & $(2.87)$ & 10.38 & 7.00 & 6.23 \\
9. & Barang lainnya & $(2.82)$ & $(0.96)$ & 3.19 & 3.00 & 1.82 & 4.21 \\
\hline
\end{tabular}

Sumber: Kemenperin

"Pecking order is a hierarchy of financing that begins with retained earnings, which is followed by debt financing and finally external equity financing." (Gitman, 2009).

Menurut (Bringham dan Houston, 2006) faktor yang umumnya dipertimbangkan perusahaan ketika membuat keputusan struktur modal di antaranya stabilitas penjualan, struktur aktiva, leverage operasi, tingkat pertumbuhan, profitabilitas, pengendalian, sikap manajemen, ukuran perusahaan, dan fleksibilitas keuangan. Jurnal ini akan melihat kedua faktor yang pengaruhnya dianggap paling dominan terhadap struktur modal yaitu struktur aktiva dan profitabilitas.
Tabel 3. Jumlah Perusahaan Makanan dan Minuman (Unit)

\begin{tabular}{cc}
\hline Tahun & Jumlah Perusahaan \\
\hline 2002 & 4.559 \\
2003 & 4.551 \\
2004 & 4.414 \\
2005 & 4.639 \\
2006 & 4.722 \\
2007 & 6.615 \\
2008 & 6.341 \\
2009 & 6.560 \\
\hline
\end{tabular}

Sumber: Kemenperin 


\section{METODE}

Metode yang digunakan dalam penelitian ini adalah deskriptif verifikatif. Metode deskripsi bertujuan untuk memberikan deskripsi, gambaran, atau lukisan secara sistematis, faktual, dan akurat mengenai fakta-fakta, sifat-sifat, serta hubungan antar fenomena yang diselidiki, berdasarkan data-data yang ada. Sedangkan metode verifikatif bertujuan menguji atau membuktikan adanya keterkaitan antara variabelvariabel yang diteliti dengan melakukan uji hipotesis melalui pengolahan dan pengujian data secara statistik. Penelitian ini menganalisis adanya pengaruh struktur aktiva dan profitabilitas terhadap struktur modal sehingga dapat diperoleh gambaran yang sisitematis, faktual, dan akurat untuk menemukan persoalan dan menarik kesimpulan.

Agar model regresi menghasilkan estimator linier tidak bias yang terbaik, maka diperlukan pengujian asumsi klasik terlebih dulu. Adapun uji asumsi klasik yang digunakan adalah uji multikolinieritas, heteriskedastisitas, dan normalitas.

Uji multikolinier digunakan untuk menguji apakah pada model regresi ditemukan adanya korelasi antar variabel independen. Model regresi yang baik seharusnya tidak ada korelasi antar variabel independen. Jika terdapat korelasi di antaranya, maka dapat dikatakan telah terjadi gejala multikolinieritas. Deteksi adanya multikolinieritas dapat dilihat dari nilai VIF (Variance Inflation Factor) dan nilai tolerance $10 \%$ dan nilai VIF 10 dengan ketentuan jika nilai VIF masing-masing variabel independen $<10$ maka tidak terjadi multikolinieritas dan jika nilai tolerance $>$ $10 \%$ maka tidak terjadi multikolinieritas.

Uji heretoskedastisitas digunakan untuk mengetahui apakah varians dari residual tidak sama untuk semua pengamatan, yang menyebabkan estimator menjadi tidak efisien dan nilai koefisien determinasi akan menjadi sangat tinggi. Jika dari suatu pengamatan tersebut terdapat varians yang berbeda, maka disebut heterokedastisitas. Dalam model regresi diharapkan tidak terjadi adanya heteroskedastisitas.

Selain itu perlu dilakukan uji normalitas. Hal ini bertujuan untuk menguji apakah dalam model regresi variabel terikat dan variabel bebas keduanya mempunyai distribusi data normal ataukah tidak. Model regresi yang baik adalah yang memiliki distribusi data normal atau mendekati normal. Untuk menguji apakah distribusi data normal atau tidak dapat dilakukan dengan menggunakan uji Kolmogorov-
Smirnov dengan menggunakan taraf signifikansi 0,05. Data dinyatakan berdistribusi normal jika signifikansi lebih besar dari 5\% atau 0,05.

Data panel adalah gabungan dari data crosssection dan data time-series, maka modelnya dituliskan dengan:

$Y_{i t}=a+b_{1} X_{1 i t}+b_{2} X_{2 i t}+e$

Keterangan:

Y : struktur modal yang merupakan variabel dependen

a : konstanta, nilai $Y$ pada saat variabel independennya adalah 0

$b_{1}$ : koefisien regresi berganda antara variabel independen $\mathrm{X}_{1}$ terhadap variabel dependen $\mathrm{Y}$, bila $\mathrm{X}_{2}$ dianggap konstan

$\mathrm{b}_{2}$ : koefisien regresi berganda antara variabel independen $\mathrm{X}_{2}$ terhadap variabel dependen $\mathrm{Y}$, bila $\mathrm{X}_{1}$ dianggap konstan

$\mathrm{X}_{1}$ : struktur aktiva, merupakan variabel independen ke-1

$\mathrm{X}_{2}$ : profitabilitas, merupakan variabel independen ke-2

e : kesalahan pengganggu

Variabel-variabel penelitian yang terdiri dari struktur modal sebagai variabel terikat (Y), serta dua variabel bebas yaitu struktur aktiva (X1) dan profitabilitas (X2) menggunakan data dengan skala rasio seperti terlihat pada Tabel 4 .

Untuk menganalisis bagaimana pengaruh struktur aktiva terhadap struktur modal dan bagaimana pengaruh profitabilitas terhadap struktur modal, maka ditentukan hipotesis penelitian sebagai berikut:

Struktur Aktiva:

$\mathrm{H}_{0}: \mathrm{b}_{1} \geq 0$ tidak terdapat pengaruh yang negatif dari struktur aktiva terhadap struktur modal.

$\mathrm{H}_{\mathrm{a}}: \mathrm{b}_{1}>0$ terdapat pengaruh yang negatif dari struktur aktiva terhadap struktur modal.

Profitabilitas:

$\mathrm{H}_{0}: \mathrm{b}_{2} \geq 0$ tidak terdapat pengaruh yang negatif dari profitabilitasterhadap struktur modal.

$\mathrm{H}_{\mathrm{a}}: \mathrm{b}_{2}<0$ terdapat pengaruh yang negatif dari profitabilitas terhadap struktur modal.

Untuk menguji hipotesis tersebut dilakukan uji-t dengan tingkat signifikansi $(\alpha)$ yang ditetapkan adalah sebesar 5\% atau dengan kata lain tingkat kepercayaan sebesar 95\%, yang kemudian akan dipergunakan untuk mencari t-tabel. 
Tabel 4. Operasionalisasi Variabel

\begin{tabular}{|c|c|c|c|c|}
\hline Variabel & Konsep Variabel & Indikator & Ukuran & Skala \\
\hline Struktur Aktiva $\left(\mathrm{X}_{1}\right)$ & $\begin{array}{l}\text { Perbandingan aktiva tetap dengan total } \\
\text { aktiva }\end{array}$ & $F T A=\frac{\text { fixed assets }}{\text { total assets }}$ & $\%$ & Rasio \\
\hline Profitabilitas $\left(\mathrm{X}_{2}\right)$ & $\begin{array}{l}\text { Kemampuan perusahaan dalam } \\
\text { menghasilkan profit pada tingkat penjualan } \\
\text { tertentu }\end{array}$ & $N P M=\frac{\text { earning aftertaxes }}{\text { sales }}$ & $\%$ & Rasio \\
\hline Struktur Modal (Y) & $\begin{array}{l}\text { Perbandingan utang jangka panjang dengan } \\
\text { ekuitas }\end{array}$ & $L T D E=\frac{\text { long term debt }}{\text { equity }}$ & $\%$ & Rasio \\
\hline
\end{tabular}

Jumlah perusahaan yang menjadi objek penelitian adalah 10 perusahaan dengan rincian seperti terlihat pada Tabel 5 .

Tabel 5. Daftar Perusahaan Sampel Penelitian

\begin{tabular}{clc}
\hline No. & \multicolumn{1}{c}{ Nama Perusahaan } & Kode \\
\hline 1 & PT Akasha Wira International Tbk. & ADES \\
2 & PT Aqua Golden Missisipi Tbk. & AQUA \\
3 & PT Cahaya Kalbar Tbk. & CEKA \\
4 & PT Delta Djakarta Tbk. & DLTA \\
5 & PT Mayora Indah Tbk. & MYOR \\
6 & PT Multi Bintang Indonesia Tbk. & MLBI \\
7 & PT Prasidha Aneka Niaga Tbk. & PSDN \\
8 & PT Siantar Top Tbk. & STTP \\
9 & PT Tiga Pilar Sejahtera Tbk. & AISA \\
10 & PT Ultra Jaya Milk Tbk. & ULTJ \\
\hline
\end{tabular}

\section{HASIL}

Bagaimana perkembangan struktur aktiva, profitabilitas, dan struktur modal dari 10 perusahaan yang menjadi objek penelitian selama periode tahun 2007-2009, terlihat pada Tabel 6., Tabel 7., dan Tabel 8.

Karena penelitian ini menggunakan panel data, maka penulis menggunakan uji Haussman. Hasil pengujian dengan menggunakan uji Haussman menunjukkan bahwa nilai statistik Haussman yang diperoleh dari hasil estimasi untuk struktur aktiva adalah 4,990632; sementara untuk profitabilitas adalah 12,53119. Selanjutnya nilai statistik Haussman tersebut dibandingkan dengan nila tabel $\mathrm{x}^{2}$. Nilai $\mathrm{x}^{2}$ pada tingkat keyakinan 95\% adalah 1,145476. Maka pada persamaan regresi panel data ini menggunakan efek tetap (fixed effect model) karena hipotesis nol harus ditolak jika besar nilai statistik Haussman lebih besar dari nilai tabel $\mathrm{x}^{2}$.
Tabel 6. Struktur Aktiva Perusahaan Sampel Periode 2007-2009

\begin{tabular}{cllllc}
\hline No. & Kode Perusahaan & $\mathbf{2 0 0 7}$ & $\mathbf{2 0 0 8}$ & $\mathbf{2 0 0 9}$ & Rata-Rata \\
\hline 1 & ADES & 0,815 & 0,680 & 0,587 & 0,694 \\
2 & AQUA & 0,366 & 0,342 & 0,320 & 0,343 \\
3 & CEKA & 0,256 & 0,326 & 0,341 & 0,308 \\
4 & DLTA & 0,270 & 0,221 & 0,194 & 0,228 \\
5 & MYOR & 0,449 & 0,424 & 0,461 & 0,444 \\
6 & MLBI & 0,632 & 0,443 & 0,535 & 0,536 \\
7 & PSDN & 0,442 & 0,454 & 0,417 & 0,438 \\
8 & STTP & 0,605 & 0,567 & 0,662 & 0,611 \\
9 & AISA & 0,657 & 0,683 & 0,677 & 0,672 \\
10 & ULTJ & 0,595 & 0,525 & 0,531 & 0,550 \\
& Rata-Rata & 0,509 & 0,466 & 0,472 & \\
\hline
\end{tabular}

Sumber: Data Olahan Laporan Keuangan

Tabel 7. Profitabilitas Perusahaan Sampel Periode 2007-2009

\begin{tabular}{clcccc}
\hline No. & Kode Perusahaan & $\mathbf{2 0 0 7}$ & $\mathbf{2 0 0 8}$ & $\mathbf{2 0 0 9}$ & Rata-Rata \\
\hline 1 & ADES & $-0,277$ & $-0,117$ & 0,121 & $-0,091$ \\
2 & AQUA & 0,034 & 0,035 & 0,035 & 0,035 \\
3 & CEKA & 0,030 & 0,014 & 0,041 & 0,029 \\
4 & DLTA & 0,057 & 0,071 & 0,100 & 0,076 \\
5 & MYOR & 0,050 & 0,050 & 0,078 & 0,059 \\
6 & MLBI & 0,086 & 0,168 & 0,297 & 0,184 \\
7 & PSDN & $-0,014$ & 0,013 & 0,055 & 0,018 \\
8 & STTP & 0,026 & 0,008 & 0,065 & 0,033 \\
9 & AISA & 0,033 & 0,059 & 0,071 & 0,054 \\
10 & ULTJ & 0,027 & 0,223 & 0,038 & 0,096 \\
& Rata-Rata & 0,005 & 0,052 & 0,090 & \\
\hline
\end{tabular}

Sumber: Data Olahan Laporan Keuangan 
Tabel 8. Struktur Modal Perusahaan

Sampel Periode 2007-2009

\begin{tabular}{cllllc}
\hline No. & Perusahaan & $\mathbf{2 0 0 7}$ & $\mathbf{2 0 0 8}$ & $\mathbf{2 0 0 9}$ & Rata-Rata \\
\hline 1 & ADES & 0,228 & 0,345 & 0,776 & 0,450 \\
2 & AQUA & 0,587 & 0,564 & 0,545 & 0,565 \\
3 & CEKA & 0,269 & 0,786 & 0,631 & 0,562 \\
4 & DLTA & 0,061 & 0,059 & 0,052 & 0,057 \\
5 & MYOR & 0,212 & 0,704 & 0,543 & 0,486 \\
6 & MLBI & 0,188 & 0,105 & 0,313 & 0,202 \\
7 & PSDN & 0,870 & 0,765 & 0,382 & 0,672 \\
8 & STTP & 0,121 & 0,115 & 0,085 & 0,107 \\
9 & AISA & 0,405 & 0,669 & 0,890 & 0,655 \\
10 & ULTJ & 0,358 & 0,139 & 0,129 & 0,209 \\
& Rata-Rata & 0,330 & 0,425 & 0,434 & \\
\hline
\end{tabular}

Sumber: Data Olahan Laporan Keuangan

\section{Pengujian Multikolinieritas}

Gejala multikolinieritas dapat dilihat dari nilai tolerance dan variance inflation factor (VIF) pada kolom Collinearity Statistics pada tabel Coefficients. Jika nilai tolerance lebih besar dari 0,1 atau VIF lebih kecil dari 10, maka tidak terjadi multikolinieritas.

Tabel 9. Hasil Uji Multikolinieritas

\begin{tabular}{lcrr}
\hline & & \multicolumn{2}{c}{ Collinearity Statistics } \\
\cline { 3 - 4 } Model & & Tolerance & \multicolumn{1}{c}{ VIF } \\
\hline 1 & FTA & .986 & 1.014 \\
& NPM & .640 & 1.563 \\
\hline
\end{tabular}

Tabel 9. menunjukkan nilai tolerance setiap variabel lebih besar dari 0,1 dan nilai VIF setiap variabel lebih kecil dari 10. Jadi tidak terjadi multikolinieritas antara kedua variabel bebas tersebut.

\section{Pengujian Heterokedastisitas}

Salah satu cara mendeteksinya adalah dengan melihat pola titik-titik pada Scatterplot. Jika tidak ada pola yang jelas serta titik-titik menyebar di atas dan di bawah angka 0 pada sumbu Y, maka tidak terjadi heterokedastisitas.

Pada Gambar 1. tampak bahwa titik-titik menyebar di atas dan di bawah angka 0 pada sumbu Y, maka dapat disimpulkan bahwa tidak terjadi heterokedastisitas.

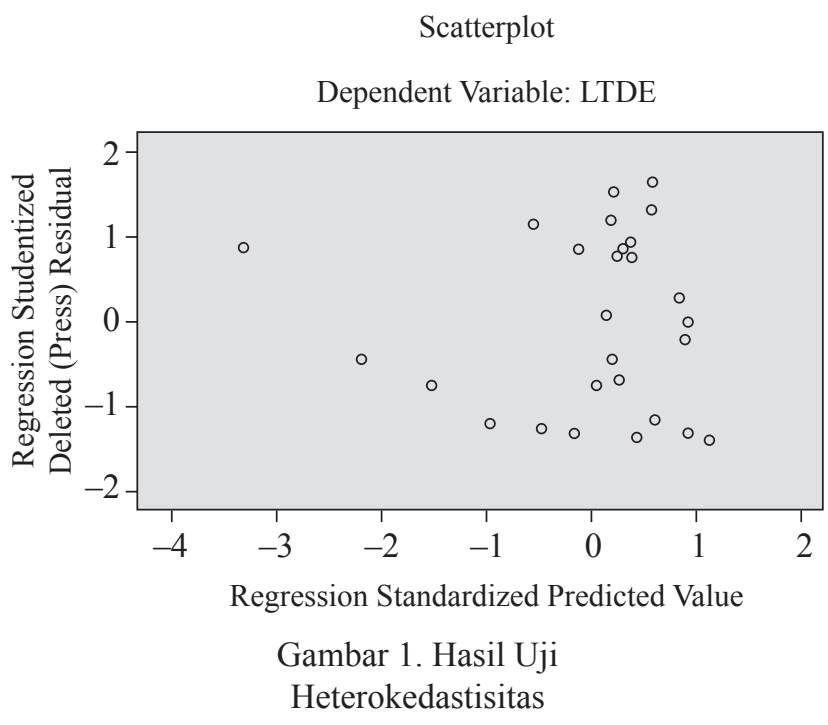

Model regresi yang baik adalah memiliki distribusi data normal atau mendekati normal. Untuk mengujinya maka dilakukan dengan menggunakan uji Normal Probability, di mana jika data pada Normal P-P Plot menyebar di sekitar garis diagonal dan mengikuti arah diagonal maka model regresi memenuhi asumsi normalitas.

Gambar 2. menunjukkan bahwa data menyebar di sekitar garis diagonal dan mengikuti arah diagonal, maka model regresi memiliki data yang berdistribusi normal atau mendekati normal.

Plot of Regression Standardized Residual

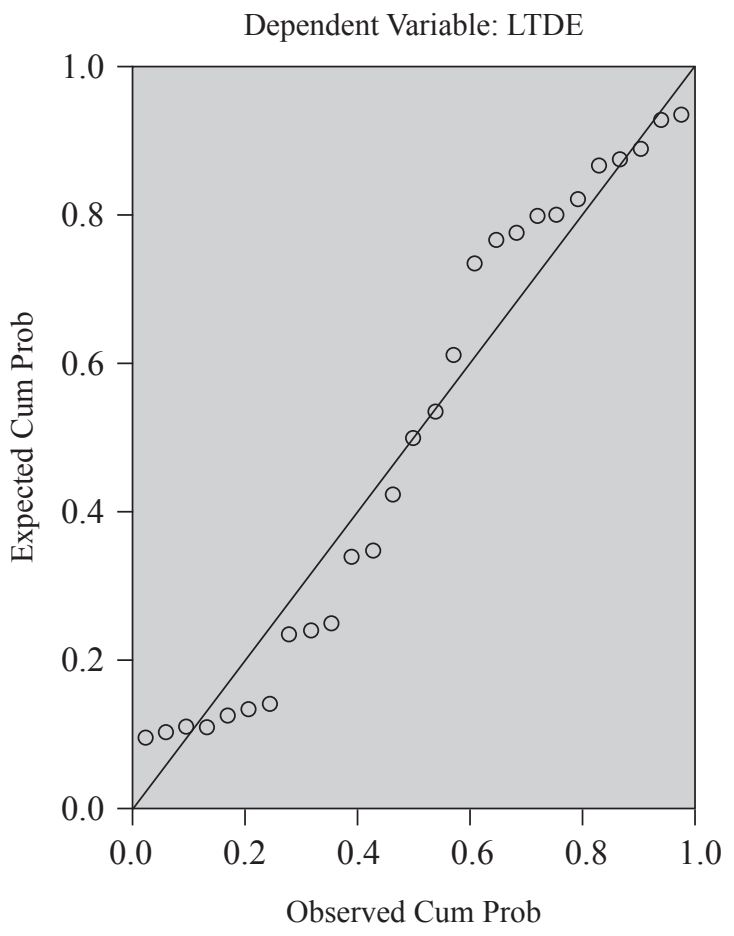

Gambar 2. Hasil Uji Normalitas 
Uji-t bermaksud untuk menguji pengaruh masing- masing variabel independen terhadap variabel dependen, yaitu antara struktur aktiva $\left(X_{1}\right)$ terhadap struktur modal $(\mathrm{Y})$ dan profitabilitas $\left(\mathrm{X}_{2}\right)$ terhadap struktur modal (Y).

Dengan tingkat signifikansi $(\alpha)$ yang ditetapkan adalah sebesar 5\% atau dengan kata lain tingkat kepercayaan sebesar 95\%, dengan tingkat kebebasan $\mathrm{df}=27$ (uji satu pihak), sehingga nilai t-tabel adalah sebesar 1,7033 .

Tabel 10. Hasil Uji Efek Tetap

\begin{tabular}{lrrrr}
\hline Variable & Coefficient & Std. Error & t-Statistic & Prob. \\
\hline C & 0.224619 & 0.207326 & 1.083410 & 0.2882 \\
FTA & 1.041337 & 0.751432 & 1.385804 & 0.0827 \\
NPM & -0.372790 & 0.149723 & -2.489868 & 0.0192 \\
\hline
\end{tabular}

Berdasarkan Tabel 10. maka model data panel dengan efek tetap adalah:

$\mathrm{Y}_{\mathrm{it}}=0.224619+1.041337 \mathrm{X}_{1 \mathrm{it}}-0.372790 \mathrm{X}_{2 \mathrm{it}}$

Struktur aktiva, $\mathrm{t}$ hitung $=1,3858$

Profitabilitas, $\mathrm{t}$ hitung $=-2,4899$

Berdasarkan hasil regresi untuk variabel struktur aktiva diperoleh t-hitung $(1,3858) \leq \mathrm{t}$-tabel $(1,7033)$, maka $\mathrm{H}_{\mathrm{o}}$ tidak dapat ditolak (diterima), sedangkan untuk variabel profitabilitas diperoleh t-hitung $(-2,4899)<$ t-tabel $(-1,7033)$, maka $\mathrm{H}_{\mathrm{o}}$ tidak dapat diterima (ditolak).

Nilai koefisien determinasi $\left(\mathrm{R}^{2}\right)$ yang diperoleh dari hasil regresi adalah 0,610 artinya perubahanperubahan yang terjadi pada struktur modal dapat dijelaskan sebesar $61 \%$ oleh perubahan-perubahan yang terjadi pada struktur aktiva dan profitabilitas, sedangkan sisanya sebesar $39 \%$ dijelaskan oleh variabel lainnya.

\section{PEMBAHASAN}

\section{Analisis Hubungan Stuktur Aktiva dan Struktur Modal}

Struktur aktiva memiliki thitung $(1,3858) \leq \mathrm{t}$ tabel $(1,7033)$, sehingga $\mathrm{H}_{0}$ diterima (tidak dapat ditolak). Jadi variabel struktur aktiva tidak berpengaruh signifikan terhadap struktur modal, walaupun hubungan antara keduanya positif. Hasil tersebut tidak sesuai dengan hipotesis awal yang menyatakan bahwa struktur aktiva berpengaruh positif signifikan terhadap struktur modal.
Hubungan positif antara struktur aktiva dan struktur modal ini sesuai dengan pendapat (Bringham dan Houston, 2006) bahwa perusahaan yang aktivanya cocok sebagai jaminan atas pinjaman cenderung lebih banyak menggunakan utang jangka panjang, artinya pemberi pinjaman (misalnya bank) lebih suka memberikan pinjaman dananya bagi perusahaan yang memiliki aktiva tetap jenis umum lebih banyak, karena aktiva tetap jenis umum seperti tanah dan bangunan lebih mudah untuk diambil alih serta dijual oleh pihak bank ketika perusahaan tersebut tidak dapat melunasi pembayaran utangnya. Di lain pihak aktiva tetap jenis khusus seperti mesin- mesin spesial kurang cocok dijadikan jaminan atas pinjaman oleh pihak bank karena aktiva tetap jenis khusus sulit dijual oleh pihak bank ketika perusahaan tersebut tidak dapat melunasi pembayaran utangnya.

Hubungan yang positif antara struktur aktiva, khususnya aktiva tetap terhadap struktur modal dijumpai pada penelitian Bereźnicka (2013) yang melakukan penelitian tentang bagaimana struktur assets berkorelasi dengan struktur modal pada beberapa jenis industri di beberapa negara Eropa. Hasil penelitiannya menunjukkan bahwa terdapat hubungan positif dan signifikan antara tangible fixed assets dengan kredit dan hutang jangka panjang. Dalam penelitian ini juga dijumpai hasil bahwa pada hampir semua jenis industri yang diteliti terdapat hubungan positif tetapi tidak signifikan antara fixed assets dengan hutang jangka panjang. Hasil lainnya memperlihatkan bahwa pada jenis industri kecil ada hubungan positif namun tidak signifikan antara tangible fixed assets dengan total debt ratio. Tidak berbeda dengan penelitian Bereźnicka, penelitian Muscettola (2014) menunjukkan bahwa tidak terdapat hubungan antara index aktiva tetap dengan tingkat leverage perusahaan yang diukur dengan rasio antara total debt terhadap net worth.

Penelitian sebelumnya yang dilakukan oleh (Zaviera, 2010) mengenai struktur modal yang mengambil sampel perusahaan telekomunikasi yang terdaftar di Bursa Efek Indonesia periode 20062009 menyimpulkan bahwa faktor struktur aktiva tidak memiliki pengaruh yang signifikan terhadap struktur modal. Hal ini kemungkinan disebabkan oleh mesin-mesin spesial (aktiva tetap jenis khusus) yang digunakan di perusahaan telekomunikasi lebih banyak proporsinya daripada proporsi aktiva tetap jenis umum. 
Jadi faktor struktur aktiva kemungkinan tidak memiliki pengaruh yang signifikan terhadap struktur modal pada perusahaan makanan dan minuman yang terdaftar di BEI periode 2007-2009, meski keduanya memiliki hubungan positif (searah). Hal ini kemungkinan disebabkan oleh beberapa hal seperti: data yang diperoleh dari laporan keuangan kurang lengkap, perusahaan makanan dan minuman lebih banyak menggunakan aktiva tetap jenis khusus sehingga pemberi pinjaman (bank) sulit memberikan pinjaman, dankemungkinan perusahaanmenggunakan modal sendiri dalam mendanai kebutuhan aktivanya.

Namun hal ini berbeda dengan penelitian (Trianty, 2008) mengenai struktur modal yang mengambil sampel perusahaan properti dan real estate yang terdaftar di Bursa Efek Indonesia periode 20042007 bahwa struktur aktiva berpengaruh signifikan terhadap struktur modal. Hal ini kemungkinan disebabkan karena perusahaan properti dan real estate lebih banyak menggunakan aktiva tetap jenis umum seperti tanah dan bangunan daripada aktiva tetap jenis khusus.

\section{Analisis Hubungan Profitabilitas dan Struktur Modal}

Profitabilitas memiliki t hitung $(-2,4899)<$ $t$ tabel $(-1,7033)$, sehingga $\mathrm{H}_{0}$ ditolak (tidak dapat diterima). Jadi variabel profitabilitas berpengaruh signifikan terhadap struktur modal dan hubungan antara keduanya bertanda negatif. Hasil tersebut sesuai dengan hipotesis awal yang menyatakan bahwa profitabilitas berpengaruh negatif signifikan terhadap struktur modal. Hal ini sesuai dengan pecking order theory yang menyatakan bahwa perusahaan dengan profitabilitas tinggi akan menggunakan utang lebih kecil karena perusahaan mampu menyediakan dana yang cukup melalui laba ditahan dengan asumsi dividen yang dibagikan pada pemegang saham adalah tetap (Mohammadzadeh et al., 2013).

Penelitian sebelumnya yang dilakukan oleh (Zaviera, 2010) mengenai struktur modal yang mengambil sampel perusahaan telekomunikasi yang terdaftar di Bursa Efek Indonesia periode 2006-2009 menyimpulkan bahwa faktor struktur profitabilitas berpengaruh signifikan terhadap struktur modal.

Penelitian Pandey (2005) yang berjudul " capital structure and firm characteristic" menyebutkan "According to the interest tax shield hypothesis, which is derived from Modigliani and Miller (1963), firms with high profits would employ high debt to gain tax benefits". Hasil penelitiannya menunjukan bahwa profitabilitas berpengaruh negatif signifikan terhadap struktur modal. Penelitian lainnya yang menunjukkan hasil sama bahwa profitabilitas yang diukur oleh return on assets (ROA) mempunyai pengaruh negatif dan signifikan terhadap struktur modal adalah penelitian yang dilakukan oleh Çekrezi (2013) dan penelitian $\mathrm{Xu}$ (2012).

Menurut Abor (2005) keputusan struktur modal adalah hal penting bagi setiap organisasi bisnis, yaitu untuk maksimisasi tingkat pengembalian. Pada dasarnya perusahaan bisa memilih banyak alternatif struktur modal, yaitu dengan meminjam utang, pendanaan sewa, dan menerbitkan obligasi. Abor melakukan penelitian tentang pengaruh struktur modal dan profitabilitas pada perusahaan yang terdaftar di Bursa Efek Ghana periode 1998-2002. Hasil penelitiannya menunjukkan ada hubungan positif signifikan antara ROE (Return on Equty) dengan struktur modal.

Niu(2008) melakukan penelitian pada perusahaan yang terdapat di Inggris dan Jerman. Hasil penelitian menunjukkan secara praktik ada tujuh faktor yang mempengaruhi struktur modal, yaitu: struktur aktiva, pajak, ukuran, profitabilitas, pertumbuhan, volatilitas, dan likuiditas.

Menurut Suhail (2008), struktur modal memiliki peran penting dalam perusahaan, karena berakibat pada financial distress, likuidasi, dan kebangkrutan jika keputusan pendanaan tidak dilakukan dengan baik. Penelitian dilakukan pada dua puluh perusahaan yang ada pada Bursa Malaysia Securities Berhad (BMSB) selama 2000-2005. Hasil penelitian menunjukkan ukuran, profitabilitas, dan bunga berpengaruh negatif signifikan terhadap struktur modal.

\section{KESIMPULAN}

Berdasarkan sampel sepuluh perusahaan makanan dan minuman yang terdaftar di BEI periode 2007-2009 dapat disimpulkan bahwa struktur aktiva mempunyai hubungan positif dengan struktur modal, namum tidak berpengaruh secara signifikan. Hal ini dapat terjadi, karena terdapat kemungkinan perusahaan menggunakan modal sendiri dalam mendanai kebutuhan aktivanya. 
Profitabilitas memiliki pengaruh negatif signifikan terhadap struktur modal pada perusahaan makanan dan minuman yang terdaftar di BEI periode 20072009. Perusahaan dengan profitabilitas tinggi akan menggunakan utang lebih kecil karena perusahaan mampu menyediakan dana yang cukup melalui laba ditahan dengan asumsi dividen yang dibagikan pada pemegang saham adalah tetap.

\section{DAFTAR PUSTAKA}

Abor. 2005. The Effect of Capital Structure on Profitability: An Empirical Analysis of Listed Firms in Ghana. The Journal of Risk Finance, 6(5): 438

Bringham, Eugene F, dan Joel F. Houston. 2006. Dasar-Dasar Manajemen Keuangan. Alih bahasa: Ali Akbar Yulianto. Jakarta: Salemba Empat.

Çekrezi, Anila. 2013. Impact Of Firm Specific Factors On Capital Structure Decision: An Empirical Study Of Albanian Firms. European Journal of Sustainable Development, 2(4): 135-148.

Gitman, Lawrence, J. 2009. Principles of Managerial Finance. Boston: Pearson Education.

Julia Koralun-Bereźnicka, Julia Koralu., 2013. How Does Asset Structure Correlate with Capital Structure? Cross-Industry and Cross-Size Analysis of the EU Countries. Universal Journal of Accounting and Finance, 1(1): 19-28.

Mohammadzadeh, Mehdi et al. 2013. The Effect of Capital Structure on the Profitability of Pharmaceutical Companies, The Case of Iran Iranian. Journal Pharmaceutical Research, 12(3): 573-577.

Mujahid, Mubeen \& Akhtar, Kalsoom. 2014. Impact of Capital Structure on Firms Financial Performance and Shareholders Wealth: Textile Sector of Pakistan. International Journal of Learning \& Development, 4(2).

Muritala, Taiwo A. 2012. An Empirical Analysis of Capital Structure on Firms' Performance in Nigeria. International Journal of Advances in Management and Economics, 1(5): 116-124.
Muscettola, Marco. 2014. Stucture of Assets and Capital Structure, What are The Relations with Each Other? An Empirical Analysis of A Sample of Italy. European Journal of Business and Social Sciences, 2(11): 55-69.

Niu. 2008. Theoretical and Practical Review of Capital Structure and its Determinants. International Journal of Business and Management.

Pandey. 2005. Capital Structure and Firm Characteristic. Journal of Financial Economics.

Ross, Stephen A., Randolph W. Westerfield, \& Bradford D. Jordan. 2009. Fundamental of Corporate Finance. New York: McGraw-Hill.

Saleem, F., \& Rafique, B. 2013. The determination of capital structure of oil and gas firms listed on Karachi stock exchange in Pakistan. Interdisciplinary Journal of Contemporary Research in Business, 9: 225-235.

Šarlija, N., Harc, M. 2012. The Impact of Liquidity on The Capital Structure: A Case Study of Croatian Firms. Business Systems Research, 3(1): 30-36.

Scott Jr., David F., John D. Martin, J. William Petty, \& Arthur J. Keown. 2008. Basic Financial Management. New Jersey: Prentice Hall.

Suhaila, Mat Kila \& Wan Mahmood, Wan Mansor. 2009. Capital Structure and Firm Characteristics: Some Evidence from Malaysian Companies. MPRA Paper No. 14616.

Trianty. 2008. Pengaruh Struktur Aktiva terhadap Struktur Modal pada Perusahaan Properti dan Real Estate yang Terdaftar di Bursa Efek Indonesia periode 2004-2007. Skripsi. Program Studi S1 Manajemen Fakultas Ekonomi Universitas Padjadjaran Bandung.

$\mathrm{Xu}$, J. 2012. Profitability and Capital Structure: Evidence from Import Penetration. Journal of Financial Economies, 106: 427-446.

Zaviera, Fika. 2010. Pengaruh Risiko Bisnis, Profitabilitas, dan Struktur Aktiva terhadap Struktur Modal pada Perusahaan Telekomunikasi yang Terdaftar di Bursa Efek Indonesia periode 2006-2009. Skripsi Program Studi S1 Manajemen Fakultas Ekonomi Universitas Padjadjaran Bandung. 